\title{
Lies, Bullshit and Fake News: Some Epistemological Concerns
}

\author{
Alison MacKenzie ${ }^{1} \cdot$ Ibrar Bhatt $^{1}$
}

Published online: 29 December 2018

(C) The Author(s) 2018

What is the difference between a lie, bullshit, and a fake news story? And is it defensible to lie, bullshit, or spread fake stories? The answers are, unsurprisingly, complex, often defy simple affirmative or negative answers, and are often context dependent. For present purposes, however, a lie is a statement that the liar knows or believes to be false, stated with the express intention of deceiving or misleading the receiver for some advantageous gain on the part of the liar. On the standard definition of a lie, the liar's chief accomplishment is deception — and it can be artful:

When we undertake to deceive others intentionally, we communicate messages meant to mislead them, meant to make them believe what we ourselves do not believe. We can do so through gesture, through disguise, by means of action or inaction, even through silence. (Bok 1999[1978]: 13)

The standard definition has, in the Western philosophical tradition, antecedents stretching all the way back to St Augustine. However, the classic definition may be too restrictive as not all lies are stated with the intention to deceive. Any number of statements can mislead through misapprehension, incomprehension, poor understanding of, or partial access to the facts. To mislead, further, is not the same as lying, or as serious, and we can rely less on a liar than we can on a person who misleads. The one who misleads may do so by "false conversational implicature" (Weber 2013: 653), expressing propositions that are not intended to be informative or to further the ends of conversation.

Lying, in contrast to misleading, can damage both credibility in assertion (the direct expression of a proposition such as that all the evidence available proves that climate

Alison MacKenzie

A.MacKenzie@qub.ac.uk

Ibrar Bhatt

I.Bhatt@qub.ac.uk 
change is a hoax) and in implicature (Weber 2013) ('I did not have sexual relations with that woman', Clinton insisted in $1998^{1}$ ). Lying attracts greater opprobrium than does misleading because the deception is intentional and the harm, potentially, is far reaching:

When we discover that someone we trusted can be trusted no longer, it forces us to reexamine the universe, to question the whole instinct and concept of trust. For a while, we are thrust back onto some bleak, jutting ledge, in a dark pierced by sheets of fire, swept by sheets of rain, in a world before kinship, or naming, or tenderness exist; we are brought close to formlessness. (Rich 1995: 192)

The deceived can feel wronged, sometimes profoundly so. Nevertheless, some lies may be necessary and morally defensible such as a prosocial lie to save a target from a hit squad. Some lies are polite untruths which are stated in order to observe etiquette and avoid injured feelings as in 'thank you for a lovely meal' which the diner found bland. And some, arguably, do little or no harm, and may avoid cruelty. A tactless 'yes' to a patient who asks if she has cancer is truthful but lacks discretion and judgement.

While not all lies should be ruled out, lying should not be promoted as a moral good. For one thing, lying can destroy trust and living in a world in which truthtelling is not common practice would be difficult, impractical, and alienating. So many of our interactions are based on trusting others to do what they will say they will do, and that they have the necessary knowledge, skills and experience they claim to have, in order that we can go about our business efficiently, with confidence and knowledge. Without trust, Baier (1986) tells us, what matters to us would be unsafe-our children, health or goods we entrust to others for safekeeping. Though we can find trust in immoral relationships, such as in a sexist marriage or an exploitative company, or for a President many of whose statements ought to be distrusted, we need trust in order to create and sustain what makes our lives meaningful. The simple Socratic truth is that no person is selfsufficient and no person is able by herself to look after all that matters to her: we need to trust and entrust to others (Baier 1986). Trust, further, 'in some degree of veracity functions as a foundation of relations among human beings' (Bok 1999[1978]: 31).

Bullshit is different from lying and it need not undermine trust, particularly when it is blatant. In his now well-known and oft-cited essay On Bullshit, Frankfurt (1985 [2005]) states that "[o]ne of the most salient features of our culture is that there is so much bullshit. And everyone knows it". With arguably the greatest bullshitter of all daily promulgating on Twitter (and other media) his assessment of the facts, truth and fakery, it is hard not to agree that we are being dumped on from on-high by no less a person than the President of the USA. In contrast to the liar who must have some regard for the truth in order to artfully subvert it, the bullshitter has no such concern or constraint. His 'focus is panoramic rather than particular. He does not limit himself to inserting a certain

\footnotetext{
${ }^{1}$ Clinton made this infamous denial at a White House press conference on January 26, 1998. The denial can be watched here: https://millercenter.org/the-presidency/presidential-speeches/january-26-1998-responselewinsky-allegations.
} 
falsehood at a specific point, and he is thus not constrained by the truths surrounding that point...' (Frankfurt 1985 [2005]) The liar and the bullshitter both pretend to tell the truth. The manipulative liar, in contrast, wants to lead us away from apprehending the truth. The bullshitter is not so scrupulous or meticulous. $\mathrm{He}$ is less concerned with how things really are, being neither for nor against truth, and often knows we know he is bullshitting. Unlike the liar, Frankfurt informs us, the bullshitter is less analytical and less deliberative, and exercises greater freedom to play around with the truth or facts. Social media seems to be the space in which we see so much evidence for these kinds of epistemic vices.

Why does there seem to be so much bullshit? In 1985, Frankfurt explained that 'the production of bullshit is stimulated whenever a person's obligations or opportunities to speak about some topic are more excessive than his knowledge of the facts that are relevant to that topic' (Frankfurt 1985 [2005]). In 2018, along with a pervasive and balkanised social media ecosystem and high internet immersion, public life provides abundant opportunities to bullshit and lie on a scale we could have scarcely credited 30 years ago. According to research carried out by the Pew Research Center (Smith 2018), social media posts tend to be overly dramatic or exaggerated versions of the truth, and people are likely to make accusations and start arguments about an issue without consideration of the facts.

Then, we have fake news. The irony of the denigratory epithet 'fake news' is that a news item described as fake need not be intentionally misleading. Brazen hoaxes, satires, pranks or parodies may be judged as 'fake' news but they need not be slurs on the truth. Often, the intention is to parody or satirise real events in order to force deception, humbug, lies and misrepresentations of the truth out into the open. They often serve social critique (or distraction). What Trump is railing against is that the news may be truthful, factual and representative of reality. He wants to undermine the trustworthiness and credibility of the news by asserting that it is 'fake' when he should, in fact, say it is 'misleading', 'incorrect', 'deceptive' or 'lying'. But perhaps this would be going too far for a bullshitter of his stature. This may indicate poor comprehension of English, or 'fake' may be easier to say or comprehend than the multisyllabic alternatives. More ominously, the assertion of fake news seems to be designed to delegitimise the press (Lakoff and Duran 2018). But a more basic truth is that fake news is any credible reporting that Trump and his adherents do not like.

Continual assertions of 'fake' news, repeated lies and endemic bullshit reduce complex and diverse realities to dangerously fatuous and nonsensical assertions. Epistemic insouciance, 'a casual lack of concern about the facts, or an indifference to whether political beliefs or statements have any basis in reality' (Cassam 2018: 2 ), may be one consequence of all the claims of fakery and bullshit. The insouciant finds it inconvenient to find out the facts and answers to complex problems. In any case, the insouciant or the sceptic might ask, 'in whom can we trust and why should we bother when we're going to be lied to anyway?' (This does not detract from the baffling fact that many of Trump's supporters appear to take him seriously. Whether they take him literally is another matter. Trumpites, like Brexiteers, may be predisposed to believe the lies.) But insouciance is no answer: it is potentially a harmful stance because it means 'not giving a shit' (Cassam 2018: 2) for the truth or the status of facts. These vices can undermine epistemic 
trust, authority and justice, resulting in epistemologies of ignorance in which the beliefs and attitudes of the listener are shaped in particular ways to suit those who seem intent on deception.

Digital environments appear to have thrown the traditional Truth-Trust dialectic into jeopardy: the sheer volume of information now makes it difficult to know what information to trust. How we come to acquire the information we encounter, and how we use it to understand the world around us, has been radically redefined since Frankfurt's (1985 [2005]) essay. Not only is there an increase in the volume of news content that is consumed on social media, but the eco-system within which it operates is also increasingly balkanised, in which networks of users will mostly read or consume information that conforms to their existing world view, and conflicting perspectives, even if they are authoritative, are suppressed. Users are increasingly reliant on algorithms and their own social media networks to determine what news, commentary and political opinion they see and consider (Bhatt and MacKenzie 2019). This is leading to the development and perpetuation of online 'echo chambers', a social epistemic structure which reinforce the beliefs of its members, and which, perturbingly, actively discredit relevant voices (Nguyen 2018). The Internet is also a place for scammers and con-artists to carry out virtual crimes with online scams such as phishing scams, 'advanced fee' fraud and even false greeting cards which look they are from friends but once clicked download malicious software onto a machine. These are egregious forms of malicious deception, of which lying is only a part. Deceivers, bots and liars, through coercive or surreptitious acts, deny control to the deceived, and by withholding or distorting information, by faking who they are, they remove the means to make meaningful choices.

The consequences are clear: lack of respect for the dignity of the person and inequality because power rests with the deceiver. Lies are a vice that affects the distribution of power, inflating the power of the powerful while reducing the power of the deceived to make informed judgements. The harm to the marginalised, to those who have legitimate claims to know the facts, to democracy, to anyone who values truth and honesty, is the perpetuation of inequality. The further harm is the spread of prejudice, confusion and distrust in institutions, news sources and figures in whom we normally have grounds to grant epistemic trust.

So why is trust important? Because truth is a prerequisite of trust, and trust, according to Macleod (2015), is necessary to any civilisation. Trust has instrumental and intrinsic value. As Bok (1999[1978]: 31) memorably states: "whatever matters to human beings, trust is the atmosphere in which it thrives". If we cannot trust, then all we may have are the starry heavens above and the moral law within us. ${ }^{2}$

Open Access This article is distributed under the terms of the Creative Commons Attribution 4.0 International License (http://creativecommons.org/licenses/by/4.0/), which permits unrestricted use, distribution, and reproduction in any medium, provided you give appropriate credit to the original author(s) and the source, provide a link to the Creative Commons license, and indicate if changes were made.

\footnotetext{
${ }^{2}$ The reference is to Kant from the Critique of Practical Reason. We borrow the thought from Baier (1986: 231).
} 


\section{References}

Baier, A. (1986). Trust and antitrust. Ethics, 96(2), 231-260.

Bhatt, I., \& MacKenzie, A. (2019). Just Google it: digital literacy and the epistemology of Ignorance. Teaching in Higher Education, 24. https://doi.org/10.1080/13562517.2018.1547276.

Bok, S. (1999[1978]). Lying: moral choice in public and private life. New York: Vintage.

Cassam, Q. (2018). Epistemic insouciance. Journal of Philosophical Research, 43, 1-20.

Frankfurt, H.G. (1985 [2005]). On Bullshit. Princeton: Princeton University Press.

Lakoff, P.G. \& Duran, G. (2018). Trump has turned words into weapons. In And he's winning the linguistic war. The Guardian, 13 June. https://www.theguardian.com/commentisfree/2018/jun/13/how-to-reporttrump-media-manipulation-language. Accessed 25 Nov 2018.

MacLeod, C. (2015). Trust. In Stanford enclyopedia of philosophy. https://plato.stanford.edu/entries/trust/. Accessed 25 Nov 2018.

Nguyen, T. C. (2018). Echo chambers and epistemic bubbles. Episteme. https://doi.org/10.1017/epi.2018.32.

Rich, A. (1995). On lies, secrets and silence. Selected prose, 1966-78. New York: W.W. Norton \& Company.

Smith, A. (2018). Algorithms in action: the content people see on social media. Pew Research Centre. http://www.pewinternet.org/2018/11/16/algorithms-in-action-the-content-people-see-on-social-media/. Accessed 25 Nov 2018.

Weber, J. (2013). Liar! Analysis, 73(4), 651-659. https://doi.org/10.1093/analys/ant081. 